\title{
"LA TEORÍA DEL CASO EN EL AÚN DENOMINADO NUEVO CÓDIGO PROCESAL PENAL"
}

\author{
Montoya PiZARro, José Alberto (*)
}

SUMARIO: 1. Introducción. -2 . Antecedentes. -3 . Glosario. -4 . La teoría del caso. 5. Doctrina comparada. - 6. Doctrina nacional. - 7. La litigación oral. -8. Análisis. - 9. Conclusiones. - 10. Recomendaciones.

\section{Introducción}

En la actualidad, a la fecha ya han pasado nueve (09) años de la puesta en vigencia del hasta ahora denominado "nиevo" Código Procesal Penal, en el cual se introduce o adecua el nuevo sistema acusatorio garantista con rasgos adversariales.

El presente artículo pretende afianzar los conocimientos básicos que se adquieren progresivamente en la universidad, a fin de poder ser empleados y aplicados en forma práctica en este proceso de cambio, que significa transitar y adecuarnos de un sistema inquisitivo mixto a otro de carácter acusatorio garantista adversarial con separación de poderes en las funciones de investigar y decidir. Para ello, a efectos de poder afrontar con claridad el contenido de esta tarea, en la formulación de las ideas básicas me he permitido cotejar algunos puntos de vista de autores competentes de conocida trayectoria, renombre y solvencia jurídica internacional, los mismos que han trabajado el tema desde una tradición académica profesional, abordando para ello diversas citas o referencias bibliográficas que permitirán sustentar mi humilde posición o visión procesal.

En la actualidad, es un tema que tiene y ha cobrado especial relevancia en el ámbito jurídico académico, a pesar que sus antecedentes se remontan desde la época de los griegos, citándose entre sus principales referentes los famosos filósofos Aristóteles y Cicerón; asimismo su principal antecedente fue el proceso [denominado juicio] a Sócrates, acto procesal en el cual por medio de la teoría del caso se efectuó o desarrollo una defensa oral [mediante el discurso] ante los magistrados, en forma concatenada, ordenada, lógica, coherente, la misma que jurídicamente podría denominarse como perfecta, a efectos de persuadir y demostrar en el foro que la posición o relato de los hechos, van a ser demostrados adecuadamente con los medios probatorios idóneos, pertinentes, amparados en fundamentos o argumentos jurídicos apropiados al caso, con lo cual se podrá contradecir, o desvirtuar la posición del antagonista.

Obviamente mucho antes de la entrada en vigencia del hasta ahora denominado Nuevo Código Procesal Penal [habida cuenta que ya tiene una vigencia de más de nueve años] de aplicación progresiva en casi todos los distritos judiciales de nuestro país, con la atingencia que en nuestra capital Lima su aplicación es meramente parcial, en razón que solo está vigente en lo atinente a los delitos de "corrupción de funcionarios". 
Es de público conocimiento que en el ya harto conocido marco del sistema inquisitivo se considera que al operador del derecho que realiza actividades jurídicas, consuetudinaria y coloquialmente se le denomina litigante. En esta humilde opinión procesal, un craso error de concepción, puesto que el solo hecho de realizar o desempeñar actividades de mero trámite judicial no implica que el operador jurídico conozca, maneje o aplique las técnicas de litigación propias del sistema procesal adversarial, actuación y desarrollo que exige y prevé de las partes procesales una adecuada preparación y manejo de las técnicas de litigación. El denominado nuevo modelo procesal penal se rige por el principio de contradicción, el mismo que hace que el proceso penal se desarrolle por medio de la expresión de un ejercicio dialéctico predominantemente oral, situación que en suma no es muy auspiciosa ni atractiva para muchos operadores jurídicos que todavía siguen las costumbres del sistema inquisitivo en el cual predomina la escribanía.

En referencia sobre el particular rol de las universidades o facultades de derecho en nuestra formación jurídico procesal, es menester citar al maestro Genaro Carrió, cuando sostiene que las "facultades de derecho nos dan conocimiento teórico de normas, y con ello, rudimentos de técnicas clasificatorias basadas en aquél conocimiento teórico. Lo demás - el oficio de abogado - tenemos que aprenderlo por nuestra cuenta" (1989: 60).

En todas las latitudes del orbe en las cuales se busca o pretende la reforma procesal penal, esta viene a representar el afán, el deseo de modernización en la administración de justicia, por ende ante la creciente expectativa de nuestra sociedad, de los operadores jurídicos (jueces, fiscales, abogados, y auxiliares de la administración de justicia). En este sentido, temas como el presente son de actualidad, puesto que la entrada en vigencia del nuevo sistema procesal será de aplicación progresiva (Decreto Legislativo $\mathrm{N}^{\circ}$ 958) en el territorio nacional. Iniciándose gradualmente en distritos judiciales como Huaura desde el 01 de julio de 2006, el año 2007 en el Callao, Lambayeque, Cusco, Ayacucho y Ucayali; el año 2008 en Piura, Tumbes, Arequipa, Cajamarca, Tacna, Moquegua, Amazonas y Junín; Obviamente a la fecha se ha implementado el Código Procesal Penal en 23 Distritos Judiciales [entre los ya referidos] regulados por la norma respectiva, de igual forma en 08 (ocho) Distritos Judiciales la antes reseñada norma procesal penal se aplica sólo para delitos cometidos de Corrupción por Funcionarios Públicos en el marco de las Leyes $\mathrm{N}^{\circ} .29564$ y 29648, este año 2013 como lo describimos en párrafos anteriores en Lima.se viene aplicando su vigencia en forma parcial.

Estos cambios y reformas implican la observancia de los procedimientos que regulan nuevos comportamientos, además exigen una nueva actitud de los operadores jurídicos y vinculados en el ejercicio profesional, desplegar una conducta radicalmente diferente a la que estábamos acostumbrados los operadores legales. Esto sin olvidar que, conforme al principio de ultractividad, las normas del antiguo sistema de procedimientos penales [inquisitivo] seguirán vigentes, a fin de regular los procedimientos orientados a resolver los procesos penales que se encuentren en trámite originados durante su vigencia.

El denominado Nuevo Código Procesal Penal, promulgado el 28 de julio de 2004 [hace nueve años], refleja un cambio en la cultura jurídica y organizativa en las instituciones vinculadas, además significa un cambio en la percepción de los operadores jurídicos sobre la forma de como ejercer laboral y profesionalmente, la expresión de cambio de la mentalidad del litigante basada en la escritoriedad, materializada en el expediente judicial, suplidas ahora por un moderno sistema de audiencias orales, públicas y contradictorias [audio y video]; situación que conlleva a la especialización en la función procesal, privilegiar o desarrollar el 
trabajo en equipo. Este sistema procesal está inspirado en el reconocimiento y la transparencia constitucional del respeto irrestricto a los derechos fundamentales de la persona, al amparo de los instrumentos internacionales de derechos humanos (convenios, tratados y pactos) los mismos que han sido incorporados al derecho interno. Con esta implementación se trata, en suma, de reemplazar el presente modelo de corte mixto (tendencialmente inquisitivo y limitadamente contradictorio), en esencia caracterizado por ser reservado, con predominio de la 'escritoriedad'. En el nuevo modelo se va a desarrollar un proceso de carácter acusatorio con rasgos adversariales, situación fáctica que involucra radicalmente un cambio en la cultura jurídica del país, también del comportamiento de las partes procesales vinculadas, ya que van a rediseñar sus roles, modificando sus conductas, métodos, practicas, usos en el proceso; por ende, avanzando, adaptándose, superando y dejando atrás el antiguo modelo inquisitivo mixto reformado.

Dentro del proceso penal, en la etapa de juzgamiento conocida o denominada comúnmente como "el juicio oral", esta es la etapa principal o fase estelar del proceso, escenario donde se van a actuar los medios de prueba ofrecidos y admitidos en la etapa intermedia por medio del debate y contradictorio conforme al debido proceso. En ese sentido los abogados (fiscalía y defensa) tenemos a nuestra disposición los instrumentos doctrinarios y jurídicos que nos permitirán ser eficientes y eficaces en el ejercicio profesional. Por ello para participar en este nuevo sistema procesal, voluntaria y obligatoriamente tenemos que aprender a estructurar, operar la teoría del caso que nos va a permitir desarrollar las estrategias de litigación oral a través de habilidades y destrezas de argumentación que van a ser expuestas oralmente ante el órgano jurisdiccional competente.

La teoría del caso se erige como el eje principal para conocer los hechos [conjunto de explicaciones jurídicas a través de proposiciones fácticas por medio de hipótesis] que posteriormente, a través del proceso, va a permitir acreditar la responsabilidad o inocencia de los procesados, escenario que podrá servir para validar nuestras tesis, al amparo de los principios acusatorio, publicidad, oralidad, inmediación, contradicción, concentración.

En este tema coincido con el maestro Tavolari Oliveros, en su prólogo a Blanco Suárez Rafael, cuando expresa: "[e]l conjunto de destrezas deben ser desplegadas sobre la base de estructuras metodológicas nuevas que faciliten el esfuerzo del litigante. La adecuada formulación de la teoría del caso, contribuye a la comprensión de los hechos, a la recopilación de las evidencias, y a su presentación en los momentos que corresponde, de modo que se constituye en el eje central de la planificación estratégica del trabajo destinado a demostrar las hipótesis o proposiciones fácticas en el juicio" (2005: 4). Dicho de manera breve por Claus Roxin: "el derecho procesal penal actúa como un sismógrafo de la Constitución" (1998:9). Considerando también que los desafíos de la globalización nos exigen estar cada vez más preparados y actualizados para enfrentar esta nueva realidad procesal.

En este orden de ideas a continuación se expone el marco teórico y conceptual que nos permitirá avanzar en la teoría del caso. 


\section{Marco Teórico}

\section{Antecedentes}

"El derecho procesal penal de los países latinoamericanos observados como conjunto, ingresó en un periodo de reformas totales, que, (...), puede compararse con la transformación que sufrió el Derecho procesal penal de Europa continental durante el siglo XIX. No se trata, así, de modificaciones parciales a un sistema ya adquirido y vigente, sino, por lo contrario, de una modificación del sistema según otra concepción del proceso penal" Julio Maier, Kai Ambos y Jan Woischnik (2000: 17).

Es materia de tratamiento genérico que el derecho procesal penal tiene sus orígenes en la Edad Media, donde predominó el sistema procesal inquisitivo. Luego posteriormente con la Revolución Francesa, se evoluciono e introdujo el modelo anglosajón por medio de un proceso de carácter público, acusatorio, contradictorio y decidido por jurados. Más adelante, con la introducción de las tradiciones germanas (Ordenanza Procesal Penal Alemana reformada de 1987, sobre todo, el Código de Procedimiento Penal de Italia de 1988), que fueron inspiradas en el sistema inquisitivo, se constituyó el sistema procesal conocido como mixto propio de los sistemas de justicia criminal europeo continentales.

El nuevo Código forma parte de la reforma procesal penal en América Latina, cuyo punto de partida más sólido fue el Proyecto de Código Procesal Penal tipo para Iberoamérica de 1978. Es allí que nuestro país, al igual que los ordenamientos procesales de Chile, Ecuador, Costa Rica, El Salvador, Puerto Rico y Colombia, como producto de la recepción, transitó de los modelos inquisitivos hacia los modelos mixtos como una alternativa; alcanzando finalmente, adecuarse al denominado nuevo modelo acusatorio garantista con rasgos adversariales acorde con los principios filosóficos imperantes en la legislación comparada.

Es pertinente citar que al hablar de legislación comparada me estoy refiriendo a los diversos ordenamientos jurídicos que rigen la legislación comparada en los diferentes países, por medio de sus Constituciones, leyes y tratados, sea en Europa, América del Norte o Latinoamérica; estas legislaciones conforman el cuerpo jurídico vigente en cada país, los mismos que son recepcionados e influyen en la orientación de nuestra legislación nacional, privilegiándose en estos el respeto al debido proceso y la presunción de inocencia; siendo que en los últimos códigos se define y aparta la función de los magistrados [órganos jurisdiccionales] en la investigación y posterior juzgamiento; este es el punto de partida o nacimiento de la figura del juez instructor, distinto del órgano jurisdiccional sentenciador, esto a fin de acrecentar, garantizar el nivel de imparcialidad del juzgador. De igual forma, en los diferentes países de Latinoamérica, al Ministerio Público se le ha dotado de las facultades $\mathrm{y}$ atribuciones de dirigir la investigación en forma exclusiva, conducir y controlar el accionar de la policía, formular acusaciones y sostener la pretensión penal en juicio; pero el eje central de esta reforma está constituido por la instauración del juicio oral al amparo de los principios constitucionales del proceso y del procedimiento.

En nuestra visión el objetivo primordial del nuevo esquema procesal penal es velar por el conjunto de derechos y garantías que se generan a nivel constitucional, e igualmente a nivel de los tratados internacionales. Este nuevo modelo procesal implica cambios radicales en los roles, conductas y/o comportamientos de los sujetos procesales, además de su 
adaptación a la cultura jurídica, por medio de un ejercicio profesional fundamentalmente estratégico que tiene su esencia en la denominada teoría del caso.

Sobre el particular, en Latinoamérica, tratadistas de la calidad de Andrés Baytelman, Mauricio Duce, Genaro R. Carrió, Héctor Quiñones Vargas, Alberto Binder, Paúl Bergman, Rafael Blanco Suárez, María Horvitz Lennon y Julián López Masle, se refieren doctrinariamente y ampliamente sobre la teoría del caso, coincidiendo básicamente con lo antes citado por el suscrito.

\section{Glosario}

\section{Teoría:}

Del griego "teoría" (etimológicamente "contemplación", sentido en el que se encuentra en la filosofía de Platón y Aristóteles). "Aristóteles lo utilizó para referirse al más elevado grado de conocimiento, en oposición al conocimiento práctico ("tecné"), adquiriendo pronto el significado de conocimiento especulativo". En www.webdianoia.com/glosario/main.php. del o1 noviembre de 2006.

La teoría es un tipo de conocimiento, es un sistema proposicional en el cual se ha establecido una conexión lógica. Las teorías están organizadas en conceptos, y el concepto es o sirve para pensar y se le define como la unidad mínima de pensamiento.

Se define así al término o denominación empleada comúnmente para referirse a cualquier idea con independencia del alcance, campo o especialidad que ella abarque; esta designación comunica e informa una posición respecto a las ideas que se aceptan como teorías científicas adecuadas y formuladas sobre la base de criterios rigurosos de conformidad con las limitaciones de los estándares científicos.

"Una teoría científica es una entidad abstracta que constituye una explicación o descripción científica a un conjunto relacionado de observaciones o experimentos. Una teoría científica está basada en hipótesis verificadas múltiples veces por grupos de científicos individuales. Abarca, en general, varias leyes científicas, engloba los conocimientos aceptados por la comunidad científica del campo de investigación y está aceptada por la mayoría de especialistas". es.wikipedia.org/wiki/Teoría. 03 noviembre de 2006.

Concurrente con lo señalado en los enunciados anteriores, el maestro Norberto Bobbio expresa: "Toda teoría puede ser considerada desde el punto de vista de su significado ideológico o desde el punto de vista de su valor científico.

Como ideología, una teoría tiende a afirmar ciertos valores ideales y a promover ciertas acciones. Como doctrina científica, su fin no es otro que el de comprender una cierta realidad y explicarla" (1998: 22-23).

Se entiende entonces, que la teoría es el conjunto de conocimientos que explican aspectos de la realidad y ese conjunto de conocimientos puede tener como características la rigurosidad, coherencia interna, sin contradicciones, la misma que se construyó como resultado de la elaboración de un conjunto de operaciones intelectuales expresadas en hipótesis. 


\section{Caso:}

Se denomina así a la descripción pormenorizada y exhaustiva de una situación real, que ha sido investigada y debe ser suficientemente clara de modo tal que facilite a los vinculados un amplio análisis e intercambio de ideas acerca de la misma [sea en materia constitucional, civil, penal y o adnistrativo]. Cábeme precisar que para el análisis y solución de un caso [situación fáctica], debe propiciarse un ambiente que permita la discusión y toma de decisiones acerca de las acciones más adecuadas a promover, orientadas a la solución del problema o conflicto en exposición.

Esta situación nos va a demostrar que, dentro de lo posible, se debe evitarse la creación de un medio estático, inerte, en el que más allá de discutir seriamente el problema de estudio, se llegue sólo a criticar el accionar de los demás.

Específicamente sobre el tema, el maestro Genaro R. Carrió dice: "En una primera caracterización es menester destacar que con la palabra 'caso' se hace referencia a un problema práctico. (...) Los casos jurídicos, vistos desde el punto de vista de los abogados, tienen algunas semejanzas con los problemas de ajedrez. (...) Las diferencias entre un caso jurídico, visto desde el punto de vista de un abogado, y un problema de ajedrez, son sin embargo inmensas. (...) Pero no podemos prescindir de esas diferencias, aunque no falten juristas, algunos de ellos de gran prestigio, que se empeñan en mirar los casos jurídicos como si fueran problemas de ajedrez - por lo menos cuando escriben acerca del derecho- y en querer enseñarnos a resolver los primeros como si tratara de dar solución a los segundos" (1989: 22, 29, 30,34).

\section{Litigar:}

Se puede citar que comúnmente se entiende como el acto u acción de pretender solucionar o enfrentar una disputa de carácter legal; como condición de tener o afrontar una disputa o querella en un proceso, al que podemos referirnos como la "litigación".

En otro sentido, también se puede aludir como el hecho de disputar o pelearse por alguna cosa. En este sentido, si nos disputamos algún bien o pertenencia estamos litigando, en un sentido más estricto o académico, la acción o hecho de litigar sería la de trasladar esa disputa a un proceso formal.

A quien participa en el proceso sea como actor, demandado o tercero. Pleitear, disputar en juicio. (Pleito, contienda, disputa) Enciclopedia Jurídica Ameba. Tomo XVIII. Pleitear, disputar en juicio sobre una cosa. Diccionario Enciclopédico Larousse. Tomo I. "el abogado defensor por su lado, tiene en sus manos todas las herramientas para ejercer su oficio. La carga de la prueba de culpabilidad la tiene el fiscal. La persona acusada de un ilícito tiene derecho a guardar silencio sobre los hechos que se le acusa y tiene derecho a ser considerada inocente mientras el fiscal no destruya dicha presunción. Ello incluye la garantía que su silencio no puede ser comentado en su contra por el acusador. El imputado, a través de su defensor, según el derecho de defensa, puede contra interrogar a los testigos de cargo. Este es el derecho a la contradicción y se debe ejercer por medio del 'contra interrogatorio', cuya finalidad principal es atacar el testimonio del testigo de la parte adversa o restarle credibilidad frente a los ojos del juzgador, entre otros" Quiñones Vargas (2003: 3). 


\section{Estrategia:}

El significado del término estrategia tiene sus raíces u orígenes en la palabra griega strategos, o el arte del general en la guerra, procedente de la fusión de dos palabras: stratos (ejército) y agein (conducir, guiar); este es un vocablo utilizado tradicionalmente en el contexto de las operaciones guerreras. Para los militares, la estrategia es sencillamente la ciencia, el pensamiento y el arte de emplear la fuerza armada de una nación para conseguir fines determinados por sus dirigentes.

Los enfoques clásicos del concepto de estrategia la definen como un "proceso a través del cual el estratega se abstrae del pasado para situarse mentalmente en un estado futuro deseado y desde esa posición tomar todas las decisiones necesarias en el presente para alcanzar dicho estado". Complementando esta definición, el mismo Aron escribió: "Puede decirse que la diplomacia es el arte de convencer sin utilizar la fuerza y que la estrategia es el arte de vencer al mínimo costo" Raymond Aron (1962: 27).

El diccionario Larousse define la palabra estrategia como el arte de dirigir operaciones militares, habilidad para dirigir, aquí se confirma la referencia sobre el surgimiento en el campo militar, lo cual se refiere a la manera de derrotar a uno o a varios enemigos en el campo de batalla, sinónimo de rivalidad, competencia; no obstante, es necesario precisar la utilidad de la dirección estratégica no sólo en su acepción de rivalidad para derrotar oponentes sino también en función de brindar a las organizaciones una guía para lograr un máximo de efectividad en la administración de todos los recursos en el cumplimento de la misión.

\section{Tácticas:}

Esta materializara el método empleado en el planeamiento con el fin de conseguir un objetivo previamente establecido en la estrategia. Esta también referida al uso de la fuerza o como se aplican en forma eficiente y eficaz los recursos planificados.

Como aquella maniobra específica destinada a dejar de lado o vencer al oponente o competidor. Siendo este último nivel el más práctico de todos los anteriores, es en este estadio que se materializa la aplicación concreta de la fuerza contra el adversario.

\section{Argumentación Jurídica:}

Se ha dicho que argumentar significa: "ofrecer un conjunto de razones o pruebas en apoyo de una conclusión" Weston (1994: 13).

El maestro Atienza expresa que: “(...) es decir, a considerar la argumentación esencialmente como una actividad dirigida a persuadir sobre algo o a defender o atacar una tesis; el énfasis no se pone ahora en la noción de inferencia ni en la premisa (y conclusión), sino en los efectos que se trata de lograr con la argumentación. La distinción entre la concepción retórica y la dialéctica depende esencialmente de que en la actividad social en que consiste argumentar, una de las partes de la relación o ambas asuman un rol activo. La concepción pragmática tiene cierta prioridad sobre las otras dos, pero la argumentación jurídica no puede verse exclusivamente en términos retóricos y/o dialécticos".

“(...) 1. Argumentar es siempre una acción relativa a un lenguaje. (...) es uno de los juegos, de los usos, del lenguaje. (...), argumentar consiste en usar de una cierta forma el lenguaje: 
dando razones (que, por supuesto, pueden hacer referencia al mundo, a hechos) a favor o en contra de una determinada tesis.

2. Una argumentación (...) presupone siempre un problema, una cuestión. El problema es lo que suscita la necesidad de argumentar, de enrolarse en una actividad lingüística dirigida precisamente a encontrar, proponer, justificar... una solución, una respuesta al mismo. Esas cuestiones, como veíamos, pueden ser de índole variada: teórica o práctica, real o hipotética, concreta o abstracta... Pero parece que en relación con cualquier argumentación, como quiera que se entienda, siempre es posible preguntarse: ¿a qué cuestión trata de contestar el argumento?

3. Hay dos formas características de ver la argumentación: como un proceso, como una actividad (la actividad de argumentar) y como el producto o el resultado de la misma (los enunciados o las preferencias en que consiste o en que se traduce la argumentación: los argumentos). (...) Desde la primera perspectiva, la argumentación puede considerarse como toda aquella actividad que ocurre entre un término a quo, el problema, y un término ad quem, la solución, la respuesta al mismo. Pero si nos situamos en la segunda de las perspectivas, la argumentación viene a ser el conjunto de los enunciados (o, quizás mejor, de las entidades) en las que cabe distinguir siempre tres elementos: las premisas (aquello de que se parte), la conclusión (aquello a lo que se llega) y la inferencia (la manera como están unidas las premisas y la conclusión, la relación que existe entre ambos tipos de entidades).

4. Finalmente, argumentar es una actividad racional no solo en el sentido de que es una actividad dirigida a un fin, sino en el de que siempre hay criterios para evaluar una argumentación, siempre parece tener sentido preguntarse si un argumento es bueno o malo, aparentemente bueno pero en realidad malo, mejor o peor que otro, etc.

Por supuesto, "bueno" está utilizado aquí en un sentido muy general (si se quiere como un concepto), de manera que los criterios de bondad (las concepciones de lo bueno) no son los mismos: según como se contemplen los argumentos, a veces "bueno" querrá decir válido (deductivamente o inductivamente válido), otras veces sólido, fuerte, relevante, eficaz, persuasivo, etc." (2006: 9, 72-76).

\section{Eficacia:}

El ilustre maestro Garzón Valdés, sobre esta definición, nos dice que: “A menudo las expresiones 'cumplimiento' y 'eficacia' son utilizadas por los juristas como sinónimas. Sin embargo, el término 'eficacia' plantea algunos problemas de los que no somos conscientes cuando utilizamos el término 'cumplimiento'. Una razón de ello es que el universo del discurso que constituye el objeto de estudio de la ciencia jurídica está constituido por un conjunto de elementos a los que generalmente se asigna una cierta clase de propiedades. Una de tales propiedades es la denotada por el término de 'eficacia"” (1977: 65).

\section{La teoría del caso}

"Para trabajar con casos concretos, reales o imaginarios, hay que disponer de una abundante gama de ellos, que cubra una parte importante del espectro de casos en que suelen verse envueltos los abogados [delitos contra el patrimonio (robo, robo agravado, hurto agravado; apropiación ilícita). Hay que disponer también de mucho tiempo, ese método requiere una lenta y paciente elaboración. (...) En otras órbitas de cultura jurídica - me refiero al mundo anglosajón - las facultades de derecho enseñan los rudimentos del oficio de abogado con 
ayuda del método del caso o case method. Este consiste en ir presentando los principales problemas que se suscitan en la aplicación y manejo de reglas jurídicas tal como se los ve a partir de casos concretos en cuya decisión gravitan las soluciones que se dé a esos problemas.

En lugar de considerar que los casos sirven únicamente para ejemplificar reglas aprendidas con independencia de ellos, se entiende que el verdadero alcance y función de las reglas solo pueden ser captados a partir de los casos" Genaro R. Carrió (1989: 52-54).

En lo concerniente al nuevo modelo procesal penal peruano y los cambios que este innova sustancialmente por medio del Código Procesal Penal, la teoría del caso se vislumbra como la visión, estructuración ordenada, diseño técnico de la estrategia que efectúan las partes procesales en el marco del proceso conforme a sus objetivos e intereses desde el momento mismo en que toman conocimiento de los hechos [delitos contra el patrimonio (robo, robo agravado, hurto agravado; apropiación ilícita); delitos contra la vida el cuerpo y la salud (homicidio, homicidio calificado, lesiones etc.); delitos de corrupción de funcionarios (peculado, cohecho, checo pasivo, cohecho activo, etc.); delitos contra la libertad sexual (violación de menor, etc)], razón por la cual hay que conocer también de la teoría del delito, de los tipos penales; a fin de poder explicar en forma eficiente y eficaz, logrando convencer en forma oral al juez (tercero imparcial) de que el relato que se les narra o hace llegar es la explicación más verosímil de lo sucedido, el cual será refrendado o probado [probatorio] en el ínterin o decurso del proceso, al amparo de los argumentos jurídicos.

Esto implica que las partes deben diseñar y desarrollar adecuadamente su perspectiva estratégica, situación fáctica que van a asumir en el proceso penal los sujetos involucrados (fiscalía y defensa), escenario en el cual por medio de los alegatos de apertura expondrán oralmente sus versiones y efectuarán una elaboración, construcción clara y precisa (exposición-relato) de los hechos por medio de proposiciones fácticas que sustenten la teoría del caso, demostrando en los hechos su pericia, eficiencia (habilidades y destrezas), explotando fortalezas, potenciando las debilidades (FODA), condiciones y habilidades que les permitirán tomar las decisiones y/o convenciones que amerite el caso; estas se expresarán al amparo del principio de contradicción, en lo referente al rol del Ministerio Público que ostenta la titularidad de la acción penal, su pretensión punitiva a efectos de obtener la condena; en el caso de la defensa, por medio de sus alegatos en contrapartida u oposición a la pretensión punitiva del fiscal a fin de lograr la absolución del procesado; las partes procesales deberán afrontar su responsabilidad elaborando y poniendo en práctica un planeamiento y planteamiento adecuado y eficiente en el desarrollo del examen y contraexamen (técnicas de interrogatorio y contrainterrogatorio), sustentado con argumentos jurídicos, medios de prueba idóneos, pertinentes (documentos, testigos y peritos), asumiendo su rol eficazmente en cada una de sus actuaciones procesales, desplegando sus mejores técnicas de litigación y argumentación oral, que quedarán acreditadas mediante un manejo adecuado de la actividad probatoria sea en el ejercicio de la acusación como de la defensa, así como de las objeciones que se puedan plantear en el desarrollo del proceso; ya que aprender y ejercer el arte de litigar es saber controlar la prueba a fin de que en los alegatos finales logre el objetivo fundamental, que es el persuadir al órgano jurisdiccional de la inocencia o culpabilidad del procesado.

\subsection{La teoría del caso como estrategia}

Cabe decir que por medio de la litigación nos vamos a proveer de las herramientas jurídicas adecuadas y eficientes para aproximarnos estratégicamente al juicio, esta permite y les enseña a los operadores jurídicos a construir teorías del caso, examinar y contraexaminar 
a los testigos, lograr extraer de ellos la información que la teoría del caso requiere para fortalecer su credibilidad o desacreditarlos relevando las deficiencias en su testimonio, cómo examinar y contrainterrogar peritos, además de conocer el manejo y la pertinencia de la prueba, etc.

“(...) litigar juicios orales es un ejercicio profundamente estratégico. Esta es una idea incómoda para nuestra cultura jurídica tradicional, pues siempre hemos concebido al juicio penal como un ejercicio de averiguación de la verdad; y siendo así, ¿cómo podría el juicio ser una cuestión estratégica? No hay nada estratégico acerca de la verdad, diría un clásico: o el imputado mató a la víctima, o no la mató; o robó el banco, o no lo robó. ¿Qué lugar tiene aquí la estrategia, que no sea más bien un intento por ocultar o distorsionar la verdad? Ésta es, más o menos, la postura que subyace a nuestra cultura tradicional.

Sin embargo, incluso cuando uno concuerda con que el mejor valor del juicio penal es distinguir quién es culpable de quién es inocente - descubrir la verdad, dirían algunos- lo cierto es que esa verdad se encuentra en un pasado que, lamentablemente, nadie puede visitar. Los hechos que componen el delito y sus circunstancias suelen ser de enorme complejidad y, entre lo uno y lo otro, para un gran número de causas lo más probable es que nunca sepamos qué fue exactamente lo que ocurrió. Incluso en aquellos casos que parecen simples o respecto de los cuales hay pruebas muy poderosas, hay zonas de la 'verdad' que probablemente nunca lleguemos a conocer: qué estaba exactamente en la mente de las personas cuando tuvieron esas conductas; cuáles fueron sus motivaciones, qué factores ocultos a la prueba determinaron los hechos tal y como ocurrieron" Andrés Baytelman, y Mauricio Duce (2005: 79).

El maestro Baytelman dice que: "la imagen de un juicio oral como un ejercicio estratégico, supone dos ideas, a saber: que la prueba no habla por sí sola y que ésta tiene su máximo aporte si se analiza en relación con la totalidad del caso. Es decir, apersonarse a un juicio no sólo se trata de hacer llegar la prueba y que el testigo relate lo que cree saber sobre hechos determinados, sino hacerle ver a los juzgadores una versión (una visión de conjunto) de los hechos y por qué motivo ese hecho o esa omisión encuadra en la pretensión jurídica que se está planteando" Capacitación como fútbol. Material del curso sobre Instrumentos para la implementación de un sistema acusatorio oral. Módulo de Capacitación para la Reforma Procesal Penal. Viña del Mar, 3 al 8 de abril de 2005.

www.cejamericas.org/documentos/cap-futbol.pdf. 07 de noviembre de 2006.

\subsection{Características}

"La teoría del caso posee algunas notas distintivas que pueden ser presentadas como rasgos a ponderar al momento de construir y optar por una teoría del caso definitiva. Nuestra Visión es que toda teoría del caso debe caracterizarse por ser: a) única; b) autosuficiente; c) verosímil, $y$ d) asociada a un valor y/o bien jurídicamente relevante" Blanco Suárez (2005: 19).

De lo anterior se desprende que la formulación de nuestra teoría del caso debe de ser única, esta debe dominar y determinar todo lo que se haga en el proceso, además debe de presentarse una versión determinada y clara de los hechos, descartando las versiones alternativas o subsidiarias que restarían credibilidad; la versión tiene que ser autosuficiente, entiéndase coherente ordenada, creíble, con lógica y sentido evitando la existencia de cabos sueltos; esta debe de proveer al magistrado un punto de vista cómodo y confortable planteado 
en términos simples que acredite la verosimilitud de los hechos narrados, aparejados de medios de prueba idóneos que generen convicción en el juzgador; asimismo debemos asociar nuestra teoría del caso con un bien o valor jurídico relevante en nuestros alegatos, por ejemplo: el respeto a la vida y los derechos fundamentales.

\subsection{Acciones para la formulación de la teoría del caso}

Para formular o plantear una adecuada teoría del caso se debe de contemplar lo siguiente: “(...) el trabajo de preparación de la teoría del caso es un ejercicio diacrónico que se actualiza a medida que se va recopilando la información, se requiere de la realización de las siguientes acciones previas a la participación en el juicio mismo. [Por lo cual] Del análisis que se realice de los [siguientes] elementos es que se podrá fijar la teoría del caso que la parte sostendrá en el juicio y construirá la estrategia a seguir. (...) Una vez definida tal teoría se deberá identificar lo que cada elemento de esa construcción aportará (...) todo lo cual deberá presentarse en una determinada secuencia (cronológica, lógica, temática, etc.), cómoda para el receptor de los mensajes:

a) Análisis detallado de los hechos: conocer en forma completa las diversas aristas de los hechos que motivan el juicio.

b) Análisis de la forma en que los hechos calzan o no en una determinada hipótesis jurídica, esto es, análisis acerca de la forma en que pueden enmarcarse los hechos en un tipo penal.

c) Desglosar el tipo penal en los elementos que lo configuran, para luego traducirlos en proposiciones fácticas.

d) Definir la evidencia que se posee para respaldar cada una de las proposiciones fácticas.

e) Debemos identificar el valor y/o bien jurídico central involucrado en el caso. Es lo que en la doctrina comparada se denomina 'el tema' del caso.

f) Debemos elaborar 'el lema' de nuestro caso, esto es, una frase breve que identifique de manera clara la cuestión central debatida en este caso. (...) Este lema debe ser utilizado por el litigante cada vez que pueda en sus intervenciones verbales ante el tribunal, particularmente al inicio y al término de sus alegatos de apertura y clausura.

g) Análisis pormenorizado de los relatos de los testigos de tales hechos (tanto los testigos propios como los de la contraparte).

h) Análisis detallado de los relatos que los peritos del caso realizan (tanto los peritos propios como los de la contraparte)

i) Análisis de otras evidencias que sirvan de fundamento a las posiciones propias y a la de la parte contraria.

j) Revisión sobre la licitud de la prueba que se desea disponer en el juicio.

k) Determinación de las peticiones que se realizarán en el juicio y los antecedentes con que se cuenta para respaldar tales planeamientos.

1) Determinación de las peticiones que se realizarán en el juicio por la parte contraria y los antecedentes con que dicha parte cuenta para respaldar sus planteamientos.

m) Posición que se adoptará frente a los argumentos de la parte contraria y elementos o antecedentes que se utilizarán para rebatir tales argumentaciones" Rafael Blanco Suárez, Mauricio Decap Fernández, Leonardo Moreno Holman y Hugo Rojas Corral (2005: 2728). 


\subsection{Factores para argumentar en un caso}

El filósofo del derecho argentino Genaro R. Carrió, sobre la teoría del caso, expresa: "Lo que diré acerca de cómo debe argumentarse un caso ante un Tribunal se limitará a observaciones muy generales, válidas —espero-, para un amplísimo espectro de situaciones. Ello es inevitable; así lo veremos seguidamente" (1989: 46-52).

1) Por nuestro 'papel' en el juicio: actor o demandado; parte querellante o defensor, etc. La importancia de esto es obvia en cuanto se liga con la carga de la prueba, con el funcionamiento de ciertas presunciones de distinta fuerza y con ciertas actitudes generalizadas de los tribunales que suelen ver con distintos ojos, por ejemplo, al querellante y al defensor.

2) Por el tipo de juicio: ¿Se trata de una causa civil, por oposición a una causa penal, o de una causa penal? ¿Se trata de un litigio en el que se ventilan preponderantemente cuestiones de derecho privado o de derecho público?, etc. La importancia de eso también es fácil de ver.

(...) En el área de las causas penales tiene vigencia principios propios de ella, tales como los que se relacionan con la regla in dubio pro reo, con la veda de la interpretación analógica, con la no admisibilidad de la prueba confesional como fundamento de una sentencia de condena si no está corroborada con prueba de otro tipo, con el rigor que tiene allí la exigencia de que la acusación debe probar los extremos de hecho que justifican la imposición de una pena, etc. Esos principios tienen manifiesto peso sobre el tipo de contenido de los argumentos que pueden usarse con eficacia en el dominio donde ellos imperan.

3) Por el tipo de escrito en que hemos de desarrollar nuestra argumentación: un alegato de bien probado; una expresión de agravios; un recurso extraordinario; una contestación de demanda en un juicio de puro derecho; etcétera.

4) Por el tipo de Tribunal frente al que debemos argumentar: un tribunal 'Tradicional' (civil, comercial, penal); un Tribunal 'no tradicional' (laboral, penal económico, contenciosoadministrativo, etc.); un Tribunal sui géneris, de carácter político (lato sensu), como la Corte Suprema de Justicia de la nación.

5) Por el contenido de la litis: ¿se debaten cuestiones preponderantemente de hecho, preponderantemente de derecho o se trata de un pleito, por decirlo así, equilibradamente mixto?

6) Por lo que razonablemente podemos esperar, dadas todas las circunstancias del caso, de la decisión judicial: la absolución de nuestro defendido o una pena baja; el éxito parcial de nuestra demanda; nada más que la extinción de las costas; etcétera.

7) Por el resultado de la prueba producida: favorable, equilibrada, desfavorable.

8) Por el estado de derecho vigente respecto de los tópicos centrales de debate claramente en apoyo de nuestra posición, claramente adverso a ella, o con mayor frecuencia, favorable en unos aspectos y desfavorable en otros, o con tendencia a orientarse en la 'buena' o en la 'mala' dirección, o bien ambiguo, indeciso, contradictorio, o aún inescrutable; etcétera.

9) Por el 'clima' del asunto concreto que tenemos entre manos: por innumerables razones; puede ser desde muy bueno hasta muy malo, pasando por un 'clima' de opaca - y a veces reconfortante- indiferencia (es un juicio más de los muchos que el Tribunal debe decidir).

10) Por las características idiosincráticas del juez: conservador; alérgico a los argumentos $x, y$ o z o a los hechos p, q o r; hedonista; sumiso; deseoso de hacerse ver; patológicamente independiente; profesoral; amigo de las especulaciones abstractas; obsesivamente religioso; etcétera. 
11) Por las características del colega-adversario: embarullador; pedante; belicoso; latero; excesivamente detallista; dado a los placeres de la retórica; autoridad en el tema sub lite, ex magistrado del fuero recientemente alejado de él; abogado de causas célebres; impulsivo abogado novel; astuto veterano de mil lides forenses; etcétera.

12) Por la incidencia probable de la decisión más allá de los límites estrictos del litigio. Esto es, su posible valor como precedente; etcétera.

Todas estas situaciones glosadas, además de otras, son importantes para saber cómo debemos argumentar y sostener nuestra posición en el proceso a fin de obtener el convencimiento y la decisión de los magistrados plasmadas en una resolución favorable, en todo caso lo más conveniente a nuestros intereses jurídicos.

\section{Doctrina comparada}

En la doctrina procesal comparada los exponentes de mayor connotación que han aportado sobre este tema son los colegas chilenos Andrés Baytelman y Mauricio Duce, quienes en sus publicaciones dicen que: "La teoría del caso es, por sobre todas las cosas, un punto de vista. Siendo el juicio penal ineludiblemente un asunto de versiones en competencia (...). La teoría del caso es un ángulo desde el cual es posible ver toda la prueba; un sillón cómodo y mullido desde el cual apreciar la información que el juicio arroja, en términos tales que si el tribunal contempla el juicio desde ese sillón, llegará a las conclusiones que estamos ofreciendo. (...) el profesionalismo de un litigante pasa precisamente por ofrecer a los jueces la mejor teoría del caso posible dada la prueba disponible.

Una vez que se tiene la teoría del caso, la regla es casi absoluta: mi teoría del caso domina todo lo que hago dentro del proceso - particularmente dentro del juicio- y nunca, nunca, nunca, hago nada inconsistente con mi teoría del caso. Todas las proposiciones fácticas que intentaré acreditar en juicio, toda la prueba que presentaré para acreditar dichas proposiciones fácticas, todo examen, contraexamen y alegato que realizo dentro del juicio están al servicio de mi teoría del caso. De lo contrario cada vez que me aparto de mi teoría del caso pierdo credibilidad, en un escenario donde 'credibilidad' es el nombre del juego.

(...) La teoría del caso es la idea básica y subyacente a toda nuestra presentación en juicio, que no solo explica la teoría legal y los hechos de la causa, sino que vincula tanto a la evidencia cómo es posible dentro de un todo coherente y creíble. (...) la teoría del caso es un producto del trabajo del abogado. Es el concepto básico alrededor del cual gira todo lo demás.

Una buena teoría del caso es el verdadero corazón de la actividad del litigante, pues está destinada a proveer un punto de vista cómodo y confortable desde el cual el tribunal pueda 'leer' toda la actividad probatoria, de manera tal que si el tribunal mira el juicio desde allí, será guiado a fallar en nuestro favor.

(...) La 'teoría del caso', en suma, es nuestra simple, lógica y persuasiva historia acerca de 'lo que realmente ocurrió'. Como tal, debe ser capaz de combinar coherentemente nuestra evidencia indiscutida con nuestra versión acerca de la evidencia controvertida que se presentará en el juicio" (2005: 95-98, 102).

De igual forma, Blanco Suárez, Decap Fernández, Moreno Holman y Rojas Corral dicen: "Una de las piezas fundamentales que todo abogado que participa en el nuevo proceso 
penal ha de tener en cuenta: el proceso de construcción de su teoría del caso, para narrar los hechos que ocurrieron al tribunal. La teoría del caso se comienza a gestar desde el primer día en que se conocen los hechos, para irse preparando mediante un proceso diacrónico durante toda la fase de investigación, hasta su formulación ante el tribunal oral en lo penal. Una buena teoría del caso permite asimismo ordenar una investigación, guiar las pesquisas policiales, evaluar el nivel de madurez de un caso para ser llevado a juicio, así como detectar los elementos faltantes para cerrar una investigación entre otros aspectos. La teoría del caso se desagrega entre las distintas proposiciones fácticas o afirmaciones de hechos que logran satisfacer de modo directo o indirecto los elementos de la teoría jurídica, esto es, los distintos elementos del tipo penal que se intenta acreditar o de la teoría jurídica de la defensa.

La teoría del caso intenta constituirse en una suerte de plantilla a través de la cual el litigante invita a los jueces a mirar la realidad, o más propiamente, los hechos del caso, proveyéndoles de un lente para dar una lectura intencionada que permitirá explicar lo sucedido. (...) corresponde a la idea central que adoptamos para explicar y dar sentido a los hechos que se presentarán como fundantes de una historia, permitiendo dar cuenta de la existencia de una determinada teoría jurídica" $(2005: 11-12,18)$.

En el mismo contexto, Thomas A. Mauet expresa: "Una teoría del caso es una clara y simple historia sobre lo que 'realmente sucedió' desde su propio punto de vista. Debe ser consistente con la evidencia no controvertida y con su propia versión de la evidencia controvertida y la aplicación del derecho sustantivo. No solo debe mostrar qué ocurrió, sino que además debe explicar por qué las personas en la historia actuaron de la manera en que lo hicieron (...). Debe ser una historia persuasiva que será la base de su evidencia y argumento durante el juicio. Si Ud. no es capaz de declarar su teoría del caso en uno o dos minutos, entonces se requiere más trabajo" (2000: 24).

De igual forma, el maestro Paúl Bergman expresa que: "Gran parte de la literatura tradicional acerca de la defensa en juicio, puede inducirnos a repensar nuestra capacidad para actuar como abogados en el juicio. Algunos sugieren que los abogados litigantes organizan y estructuran un caso, del mismo modo que los grandes dramaturgos organizan una pieza. Además, a menudo se afirma que la defensa en juicio es un 'arte', una habilidad intuitiva a la cual podemos describir solo mediante máximas e ilustraciones.

Gran parte del 'arte' de la defensa en juicio consiste en técnicas que puedan aprenderse del mismo modo que se aprendió aritmética (...). Conocer y utilizar esas técnicas nos suministrará una base sólida para formular decisiones intuitivas. Si es necesario que haya dramatismo, éste surgirá generalmente a través de la evidencia misma, sin que sea necesario que uno ejerza demasiada presión" (1989: 13-14).

El connotado procesalista Paul Bergman explica que en un juicio se procura relatar una historia que sea suficiente desde el punto de vista legal. Señala que: "la meta final en el juicio puede ser probar o refutar teorías jurídicas, éstas son abstracciones que casi siempre están distanciadas un par de pasos de la evidencia. En primer lugar, la mayoría de las teorías jurídicas son en realidad grupos de elementos. Por ejemplo la teoría del 'robo' consiste en elementos que son 'apoderarse de la propiedad ajena' y 'mediante la fuerza o el miedo'. La 'negligencia' incluye, entre otros elementos la 'conducta irrazonable' y 'la causa próxima'. [Sin embargo, los relatos de las personas por lo general no se van a dar en estos términos porque se trata de abstracciones a las que el órgano jurisdiccional en su rol juzgador llega en base a las pruebas aportadas en el proceso. De lo enunciado se desprende que, la proposición 
fáctica es una afirmación de un hecho que satisface un elemento legal y elimina la distancia entre la historia y la teoría legal. En consecuencia, para obtener determinado resultado jurídico el abogado litigante debe estructurar adecuadamente la teoría del caso que le permitirá afirmar una proposición fáctica para satisfacer cada uno de los elementos de una teoría jurídica] (1989: 21).

"El defensor también cumple la función de aconsejar a su cliente para decidir sobre los pasos siguientes a dar en el procedimiento a partir de un cálculo de probabilidades. (...) el abogado deberá atender, primero, a la información que se le suministra sobre los hechos y circunstancias del caso, luego a las normas jurídicas aplicables, tanto de índole sustantiva como a las procesales, para luego con tales elementos, prever las alternativas que conforme a su experiencia se producirán y suministrar consejo sobre lo más conveniente según la situación en que se encuentre su cliente. Por la importancia del encuadre de los hechos en el resultado del caso, la comunicación permanente entre imputado y defensor resulta indispensable: ella se garantiza expresamente durante el juicio oral (...)” María Horvitz Lennon y Julián López Masle (2002: 245).

El Tribunal Constitucional Español ha declarado sobre el tema que: "en todo proceso judicial debe respetarse el derecho a la defensa contradictoria de las partes contendientes o que legalmente debieran serlo, mediante la oportunidad dialéctica de alegar y justificar procesalmente el remedio judicial de sus derechos e intereses" (...) "en todo proceso judicial debe respetarse el derecho a la defensa contradictoria de las partes contendientes, a quienes debe darse la oportunidad de alegar y probar procesalmente sus derechos" Alex Carocca Pérez (1998: 95).

\section{Doctrina nacional}

En nuestra sede, se puede citar el artículo que sobre este tema ha efectuado el maestro Arsenio Oré Guardia, en una revista jurídica, cuyo tenor dice que: "en este esquema surge la teoría del caso, la cual debe estar diseñada para convencer a los jueces de que la versión que se entrega es la más fidedigna de los hechos y la interpretación más adecuada y justa" (2005: $13)$.

\section{La litigación oral}

Con la entrada en vigencia del hasta ahora denominado nuevo modelo procesal penal, por la condicionante técnica [habilidades - destrezas] en la redistribución de los roles jurídicos al ínterin del proceso, constantemente se le forma un nudo en la garganta a muchos de los operadores de derecho, sean abogados o miembros del Ministerio Público, debido a que se presenta la obligación de adaptarse a este modelo, cuyos requisitos y características se sustentan en los principios constitucionales que rigen el proceso como son: la publicidad, el acusatorio, la contradicción, el debate y, principalmente la oralidad, situación y actuación fáctica a la que la mayoría de colegas litigantes no están acostumbrados, valgan verdades, debido a la poca o escasa preparación desde las universidades, centros de formación jurídica, instituciones, asociaciones, colegios profesionales en las técnicas de litigación oral y la teoría de la argumentación; la teoría del caso, el maestro Arsenio Oré la propone de la siguiente manera: "la litigación oral es un ejercicio profundamente estratégico en la que cada parte, Fiscal y Defensor, diseñan su estrategia y desarrollan su actividad para hacer prevalecer su versión ante el juez" (las cursivas son nuestras) (2005: 13). Lo que va a permitir que los abogados y fiscales, para desempeñar su rol, desarrollen una adecuada estrategia para exponer cómo acontecieron los hechos. 
En este acápite, el maestro costarricense Quesada Pacheco expresa lo siguiente: "Así, el uso del discurso escrito ha sido la tradición en este procedimiento judicial y abandonar las costumbres siempre es difícil; lo innovador causa algún grado o mucha incertidumbre, o incluso, rechazo, hasta que se logran comprobar las bondades que acarrea $y$, en ese momento, se adquiere la conciencia de las necesidades de laborar con lo nuevo. Precisamente, el trabajo en las audiencias y en los juicios orales conlleva una nueva forma de recabar información e implica la utilización de nuevas maneras de análisis, pues el texto escrito difiere en gran medida del discurso oral" Jorge Arturo Quesada Pacheco (2002: 169).

"Un jurista que no sabe litigación —litigante, juez o profesor de derechosimplemente elabora teorías abstractas, intelectuales, que no responden a la realidad, a los problemas y valores para los que dichas normas fueron diseñadas. Y con demasiada frecuencia esto - en América Latina lo sabemos bien-desnaturaliza el proceso, lleva a lecturas lineales y literalistas de las normas, equivoca las interpretaciones, genera requisitos absurdos o bien los estima satisfechos con cumplimientos puramente formales" Andrés Baytelman y Mauricio Duce (2005: 13).

"Muchos abogados educados y formados en el sistema acusatorio adversativo conocen a la perfección las técnicas de litigación oral. Sin embargo, cuando llega el momento de aplicarlas, a una gran cantidad de ellos se le hace difícil ejecutarlas éxito. En mi opinión, ello se debe a que de nada sirve conocer las técnicas de litigación oral si no se posee la personalidad adecuada para ponerlas en práctica.

Hay una serie de cualidades o rasgos de personalidad que, a mi entender, debe tener toda persona que desee adentrarse con razonable éxito, en el campo de la litigación oral" Héctor Quiñones Vargas (2003: 134).

Es necesario entonces la litigación oral en el proceso, como eje básico de la sociedad en la cual vivimos, por los constantes cambios en los cuales estamos inmersos, los mismos que hacen necesario que nuestros operadores del derecho se hallen convenientemente preparados. Tal y como lo manifiesta el antes referido profesor peruano de derecho procesal penal, cuando expresa que: "en el juicio oral rige el principio de contradicción. El Fiscal y el defensor exponen sus versiones en los alegatos de apertura, en los interrogatorios y en los alegatos de cierre" (Oré Guardia, 2005: 13). De modo que al hacer uso de este medio con la seriedad y la eficiencia adecuada implica el estar al corriente para trabajar y desenvolverse en sistemas adversariales, por lo que la oralidad se convierte en una de las herramientas o instrumentos más eficaces en la producción y comunicación de información entre las partes mediante el uso de la palabra, que asegura la inmediatez y la publicidad en el proceso, principios que se encuentran plasmados en nuestro ordenamiento jurídico y son de alcance constitucional.

\section{Análisis}

Un adecuado y ponderado estudio de los antecedentes históricos del rumbo procesal nos debe prevenir para que no pretendamos apriori que el hecho de haber adoptado el sistema acusatorio garantista con rasgos adversariales implica una superación completa del anterior sistema inquisitivo; lo que va a diferenciar a un sistema procesal de otro, es el mayor o menor grado de adversariedad, ya que con la entrada en vigencia del nuevo Código Procesal Penal cada parte procesal debe desempeñar a cabalidad su rol, lo que implica que cada parte debe diseñar o estructurar su teoría del caso, por medio de la puesta en práctica de un conjunto de 
habilidades y destrezas, situación de hecho que acorde con nuestra realidad todavía no se consigue en forma óptima el nivel de preparación que requiere este sistema procesal.

Con la entrada en vigencia del nuevo Código se plantea el desarrollo de un modelo procesal penal de corte acusatorio adversarial, predominantemente oral y público, con predominio del principio de contradicción; razón por lo cual se exige la concreción de la igualdad procesal, por ende admite una efectiva participación de las partes en el proceso; asimismo se va a redefinir los roles de los juzgadores, del Ministerio Público, los abogados y la policía; se define y afirmar una serie de facultades funcionales del Ministerio Público, por medio de mecanismos de simplificación procesal y soluciones alternativas a fin de optimizar la función de la fiscalía; asimismo se reconoce las garantías del debido proceso como eje central del desarrollo del mismo, con la finalidad de remediar las deficiencias de nuestra justicia penal.

La teoría del caso en esencia facilita y optimiza la estrategia de las partes, al promover la terminación anticipada de los procesos (principio de oportunidad, las convenciones y acuerdos reparatorios), teniendo como objetivo primordial la celeridad y economía procesal, a la vez que enerva el descongestionamiento de los penales debido a la presencia de presos sin condena, la optimización de los procesos y el logro del cambio de imagen de la administración de justicia, devolviéndole la confianza ante los usuarios del servicio de justicia y la sociedad en general.

Es pertinente señalar que, conforme a la experiencia de la legislación comparada en Latinoamérica, un sistema acusatorio adversarial penal en parangón con un sistema mixto tendencialmente inquisitivo y limitadamente contradictorio como el nuestro, reduce los plazos del proceso. No obstante, cabe precisar que en términos de eficacia, el principal reto consiste en lograr elevar positivamente las estadísticas de casos juzgados; asimismo, perfeccionar la calidad del juzgamiento. Para alcanzar ese objetivo, entre otros factores tiene una especial relevancia la adecuada y oportuna formación del operador jurídico, la preparación y capacitación que en estos momentos de transición pueda brindarse a los jueces, fiscales y defensores es de vital importancia, ya que el conocimiento de los hechos y del derecho a aplicarse es una necesidad básica para la estructuración de la teoría del caso.

Al respecto, el maestro Carrió nos dice: "Uno de los defectos graves de la forma como se enseña el derecho en nuestras universidades es que, por lo general, no se lo presenta desde ninguno de esos puntos de vista que permiten ver al derecho en un contexto práctico. (...) En nuestras facultades, donde no se enseña según el método del caso, no se enseña - ni se comienza siquiera a enseñar- el oficio o profesión de abogado. Uno tiene que aprender el oficio solo, después de graduado, a costa de las desagradables experiencias (...) y ocasionalmente, con perjuicio para el bolsillo de algún cliente que cayó en el error de considerar que nuestro dinámico optimismo de profesionales jóvenes y entusiastas — muchas veces postizo - era índice seguro de idoneidad profesional y garantía de éxito en la gestión encomendada" (1989: 56).

Sobre este tema, en opinión de los autores señalados, conforme a las experiencias resultantes en sus países, lamentablemente persiste la falta de preparación y adiestramiento de nuestros operadores jurídicos, sobre todo en la enseñanza de la teoría del caso y de sus componentes (fáctico, jurídico y probatorio), ya que, conforme se desprende de la doctrina citada en el cuerpo del artículo, la teoría del caso es el planteamiento de las partes, imponiéndose la teoría que está estructurada coherentemente, suficientemente probada y 
debidamente argumentada conforme a las técnicas de litigación oral y argumentación jurídica que prevé el nuevo modelo procesal y que sirven como herramientas en manos de las partes para desarrollar y cimentar su teoría.

También es menester enunciar la ausencia de coordinación interinstitucional, la falta de interés de las universidades con sus respectivas facultades como responsables de la formación académica [elección de docentes sin nivel o experiencia, además de no contar muchos de ellos con la especialidad o calificación], así como la escasa difusión de la ejecución e implementación gradual del Código Procesal Penal en los diversos distritos judiciales.

El problema de la capacitación y enseñanza para la ejecución del cambio nos lleva a preguntarnos si es por la falta de recursos económicos [situación que es evidente a la fecha], falta de tiempo, falencia tecnológica, formación deficiente de los operadores, etc. La principal dificultad se halla en el ineficiente modelo pedagógico que se tiene en el proceso de enseñanza y aprendizaje. Es por ello que la capacitación para la reforma procesal penal no será eficaz en tanto no cambie su lógica de intervención. Siendo que, una de las primeras dificultades que se representan en la capacitación es la propia tradición en materia de adiestramiento jurídico. Desde esta nueva perspectiva, la capacitación jurídico procesal debe preocuparse por otorgarles a los operadores del derecho vinculados al proceso (juez, fiscal o defensor) las reglas básicas para que obtengan las capacidades necesarias para su rol, en un escenario lo más parecido a la realidad. La metodología clave es la simulación de casos reales asistiendo como espectadores a la práctica cotidiana.

Como colofón a este párrafo, no puedo soslayar en este análisis el comentario del colega César Eugenio San Martín Castro, vertido en su conclusión de Informe Nacional de Derecho Penal, donde enunció que: "el sistema de justicia nacional padece deficiencias muy marcadas que están lejos de superarse en el mediano plazo. Si bien se ha potenciado el nivel administrativo de la justicia (se ha ganado en recursos financieros, humanos y tecnológicos), aun cuando falta mucho por hacer, existen sensibles problemas vinculados al respeto de las garantías y principios de la administración de justicia que el actual modelo de reforma, no ha podido o sabido enfrentar. En esta perspectiva, la promulgación de un nuevo Código Procesal Penal, ante una carrera judicial y fiscal aun no estabilizada y consolidada, dado el alto índice de jueces y fiscales provisionales y una falta de firmeza de la jerarquía judicial para afirmar los fueros de la jurisdicción y evitar la expansión ilegítima de la justicia castrense, no se presenta muy provisor, habida cuenta de una presencia excesiva, por decir lo menos, de los órganos de seguridad y fuerzas del orden y una ostensible debilidad institucional del Ministerio Público y el Poder Judicial, que preludia un control muy escaso de los excesos de la policía y una insuficiente afirmación de las garantías constitucionales del individuo sometido al proceso" Julio Maier, Kai Ambos y Jan Woischnik (2000: 710711).

Con la reforma actual de nuestro sistema procesal penal, a mi modesta opinión la conclusión predictiva de nuestro colega San Martin Castro, fue desacertada y hasta falaz, su contenido y la realidad actual en este 2013, me relevan de comentarios, con mayor razón preguntándonos conforme a las reflexiones y críticas que hizo él en su condición de magistrado judicial, a efectos de lograr revertir la situación que criticaba, porque cuando fue elegido como Presidente de la Corte Suprema hasta el 2012, no lo logró, además de que como explica que durante su gestión como máximo representante del Poder Judicial, no logro la implementación total y lograr la plena vigencia del nuevo modelo procesal en el 
distrito judicial de Lima y el Callao, algo que podría parecer hasta anecdótico, habida cuenta de sus promesas y de todo lo que le escuchamos decir por los medios de difusión.

\section{Conclusiones}

- Con la vigencia del nuevo modelo procesal desde hace nueve años, es menester indicar que ya se ha definido y concretado los roles del órgano jurisdiccional, fiscal y la defensa. El modelo acusatorio adversarial se rige específica y taxativamente por el principio de contradicción, situación que exige y obliga a las partes a estructurar su teoría del caso, formular el diseño estratégico por medio de las técnicas de litigación oral para afrontar con éxito el casos según el tipo o conducta delictiva realizada, con el objetivo de lograr que su historia o relato sea el más creíble mediante la exposición oral de sus alegatos, el adecuado examen-contraexamen de testigos y peritos, las objeciones y plantear reglas claras sobre el debate de la actividad probatoria, además de controlar la admisibilidad de la prueba, situación que permitirá una prestación más eficiente y a menor costo para los usuarios del servicio de justicia.

- Otra de las ventajas del nuevo modelo procesal es que permite que los sujetos procesales puedan utilizar con mayor eficiencia las formas de conclusión anticipada del proceso (criterios de oportunidad, convenciones, etc.), lo que admitirá que haya celeridad y economía procesal, además de evitar la sobrecarga procesal en los despachos judiciales.

- Uno de los aspectos más críticos de este tema es el referido a la capacitación y adiestramiento de jueces, fiscales y abogados. En la actualidad, se aprecia que los operadores jurídicos no se encuentran suficientemente entrenados para cumplir sus nuevos roles y funciones, habida cuenta que este modelo procesal demanda una eficiente preparación y formación de todas las partes procesales vinculadas, a fin de que en el proceso desarrollen las habilidades y destrezas que el sistema acusatorio adversarial demanda. Asimismo es de observarse que en algunos distritos judiciales los jueces adoptan una posición ultra-garantista, lo cual abona en algunos casos en la impunidad, lo cual trae un mensaje negativo hacia la sociedad.

- En la actualidad una de las críticas en esta humilde opinión de litigante, por la modesta experiencia adquirida en el cotidiano reflejo de la actividad procesal, es que muchas veces se aprecia la desnaturalización del proceso respecto al cumplimiento de los plazos procesales, habida cuenta que hay casos en donde estos no se cumplen por diversos factores atribuibles a las partes o al director del proceso, tanto en la etapa de investigación preparatoria [preliminar y preparatoria propiamente dicha; ejemplo: Exp. $N^{\circ}$. 02030-2011- Ayacucho, desde la formalización de la investigación preparatoria hasta la audiencia de control del requerimiento de la acusación fiscal ha pasado más de 9 meses, siendo su resultado la devolución del requerimiento, continua en trámite], esto por diversos factores en la intervención del ministerio público al convertir la investigación en compleja sin expresión de causa, esto abonado al deficiente manejo de algunos operadores jurídicos [abogados] en los mecanismos de control de los plazos, así como no promover el adecuado uso de las audiencias de tutela de derechos. Obviamente la desnaturalización de los plazos también se refrenda con las sentencia casatorias emitidas para poder permitir que el Ministerio Público pueda adicionar un plazo extraordinario a su investigación. 


\section{Recomendaciones}

Asumir una nueva cultura en lo atinente a la práctica procesal adversarial; obviamente, implica capacitar eficientemente a los operadores jurídicos, a fin de proporcionarles los elementos necesarios (herramientas de interpretación, argumentación jurídica, análisis crítico de las instituciones procesales, conocimiento de las normas y principios inherentes al proceso penal, desarrollo de habilidades y destrezas de litigación propios del sistema acusatorio adversarial) para que desempeñen una adecuada actuación en sus roles; en general, básicamente, entender que el proceso penal, antes que un sistema destinado a la aplicación de penas, está orientado a la resolución de los conflictos.

Es urgente; obligatorio la preparación y el adiestramiento del futuro capital humano, desde las aulas universitarias, los colegios profesionales e instituciones que nos agrupan, para mejorar la calidad pedagógica en el manejo de la teoría del caso por medio del método de resolución de casos conforme al sistema anglosajón, conforme ya se realiza en otros países de América Latina; crear conciencia en los capacitadores y operadores del derecho [algunos lo han visto como una fuente de ingresos o negocio] en el desarrollo del arte de la oralidad y argumentación jurídica. Sin embargo, no solo se busca buenos oradores o maestros de ceremonias, sino operadores capaces de poder expresarse, hacer entender y transmitir sus argumentos en forma lógica y clara.

Implementar la capacitación con profesionales connotados de reconocida experiencia no solo doctrinaria, sino que sean expresamente por el desarrollo cotidiano en el ejercicio de la profesión en la práctica procesal, para principalmente transmitir destrezas para la litigación oral en audiencias orales previas al juicio oral, actividad diseñada para introducir la lógica de las audiencias en las etapas previas al juzgamiento oral, además fijar imágenes concretas de prácticas apropiadas en este tipo de audiencias casuísticas sobre el proceso, cuyo objetivo clave es desarrollar destrezas básicas de litigación oral, asimismo cambiar el paradigma de comprensión del nuevo sistema procesal penal y sus reglas.

\section{Bibliografía}

- Atienza, Manuel (2006) El derecho como argumentación. Concepciones de la argumentación, Barcelona: Ariel.

- Bergman, Paúl (1989) La defensa en juicio, Buenos Aires: Abeledo Perrot.

- Blanco Suárez, Rafael; Decap Fernández, Mauricio; Moreno Colman, Leonardo y Rojas Corral, Hugo (2005) Litigación estratégica en el nuevo proceso penal, Santiago: Lexis Nexos.

- Bobbio, Norberto (1998) Teoría general del derecho, Madrid: Debate.

- Carocca Pérez, Alex (1998) Garantía constitucional de la defensa procesal, Barcelona: José María Bosch.

- Carrió, Genaro R. (1989) Cómo estudiar y cómo argumentar un caso. Consejos elementales para abogados jóvenes. Buenos Aires: Abeledo Perrot. 
- Garzón Valdés, Ernesto (1977) "Algunos modelos de validez normativa" "Algunos modelos de validez normativa", en Revista Latinoamericana de Filosofía III (marzo 1977) 1; reimpreso como Cuaderno de Trabajo $\mathrm{N}^{\circ} 21$ del Instituto de Filosofía de la Universidad de Maracaibo (Venezuela) 1979.

- Horvitz Lennon, María y López Masle, Julián (2002) Derecho procesal penal chileno. Tomo I, Santiago: Editorial Jurídica de Chile.

- Maier, Julio; Ambos, Kai y Woischnik, Jan (2000: 710-711) Las reformas procesales penales en América Latina, Buenos Aires: Ad Hoc.

- Mauet, Thomas A. (2000) Trial Techniques. Aspen Law \& Business, Aspen Publishers, Inc., Gaihersburg/New York, $5^{\text {a }}$ edición.

- Oré Guardia, Arsenio y Loza, Giulliana (2005) "La teoría del caso", En El Portal del Derecho 10. Ayacucho, julio.

- Quesada Pacheco, Jorge Arturo (2002) Análisis del discurso oral en el proceso penal. San José: Editorial Universidad Estatal a Distancia EUNED.

- Roxin, Claus (1998) Stratverfahrensrecht, 25 edición, Beck, Münich.

- Weston, Anthony (1994) Las claves de la argumentación, Barcelona: editorial Ariel, S.A.

- www.webdianoia.com/glosario/main.php 01 noviembre de 2006

- $\quad$ es.wikipedia.org/wiki/Teoría 03 noviembre de 2006.

- $\quad$ www.cejamericas.org/documentos/cap-futbol.pdf. 07 de noviembre de 2006.

(*) Abogado, conferencista, panelista internacional; profesor investigador en la especialidad de Derecho Procesal; autor de libros ["Proceso Penal ordinario - Manual del Litigante (2011.)" y "Estructura del Proceso Penal Ordinario - Doctrina y practica aplicada al nuevo modelo Procesal Penal (2013)."] artículos en Derecho Procesal ["Litisconsorcio en el ordenamiento Civil Peruano" - Revista Abogados - Edición Especial]; con estudios de doctorado en Derecho y Ciencia Política, maestría de Derecho Procesal en la USMP, maestría en Derecho Civil y Comercial en la Universidad de San Martín de Porres (USMP), maestría en Desarrollo y Defensa Nacional en el Centro de Altos Estudios Nacionales (CAEN); estudios de Postgrado en Derecho Procesal y Sistemas Procesales Penales en la UBA Buenos Aires; Curso de especialización internacional en Interrogatorio, Contrainterrogatorio y Técnicas avanzadas de Litigación Oral en la Universidad de Medellín -Colombia. Profesor de los cursos de Teoría General del Proceso; Introducción al Derecho Civil en el Pregrado de la Facultad de Derecho de la Universidad de San Martín de Porres. jalbertmonty@hotmail.com.jmontoya@usmp.edu.pe.joalmonty@yhoo.es 